\title{
Problems Faced by Preschool Teachers When Using Teaching Aids in the Teaching Learning Process
}

\author{
${ }^{1}$ P L N Randima Rajapaksha and ${ }^{1}$ P R D Chathurika \\ ${ }^{1}$ Department of Early Childhood and Primary Education, The Open University of Sri Lanka
}

\begin{abstract}
This study attempts to find out the problems faced by the preschool teachers when making and using teaching aids in the process of teaching and learning, and to identify their perception on using teaching aids. The study employed quantitative method of research. The sample of this study comprised of 60 Sinhala medium preschool teachers and 40 English medium teachers who have registered in the Diploma in Early Childhood \& Primary Education programme in the Colombo regional center, at OUSL. The study employed the survey research design. A questionnaire was adopted to collect data. The data were analyzed using simple quantitative statistical methods. The study revealed that the teacher have precise perception of teaching aids and its functions. However they face problems such as lack of time for making teaching aids for each lesson, lack of training on using electronic teaching aids, lack of knowledge on relating teaching aids to the lesson in the teaching learning process. Thus, the study recommends enhancing more emphasis by providing awareness, knowledge on using teaching aids effectively among preschool teachers.
\end{abstract}

KEYWORDS: Teaching Aids, Preschool teachers, Teaching learning process, Perception, Problem faced by preschool teachers

Corresponding author: P L N Randima Rajapaksha, eMail: plran@ou.ac.Ik 


\section{INTRODUCTION}

The preschool education provides necessary environment to stimulate the five senses of children in the age of $3-5$ years old. In order to provide an effective simulative environment in the process of teaching and learning many factors such as children's readiness, classroom environment, teaching methods, assessments, and teaching aids make an impact. Among different factors Teaching Aids makes a direct influence on both teaching and learning. According to Romiszowski (1968) teaching aids are defined as instruments which facilitate the process of teaching learning.

One responsibility of the teacher is to organize and present the task to be learned in such a way that learners can assimilate it as efficiently and rapidly as possible (Spencer, 1988 \& Jacobs, 1996). Teachers must therefore put learners in to adequate and appropriate sensory contact with the concepts to be learnt (Maduna, 2002). Having access to wide variety of teaching aids will assist individual teachers in finding ways of modifying their instructions to fit the diversified needs of their learners (Maduna, 2002).

There is a relationship between the child's state of development and the process of acquiring, organizing, retaining and using knowledge (Lindeque, 1996, Mwamwenda , 1994 \& Spencer, 1988). Any type of teaching aids will not be appropriate for all level of learners. Therefore teaching aids must be suitable for particular group of learners (Yule \& Steyn, 1991 and Van Rooyen \& Van der Merwe, 1996).

Thus the teachers have to prepare teaching aids that serve the objectives of the particular lesson.

However, it is possible that wrong perceptions about the teaching aids and their incorrect use by the teachers may lead to ineffective teaching learning situations (Van Rooyen \& Van der Merwe, 1996). When teachers enter schools without this valuable information and when they are faced with reality they end up producing teaching aids that are technically bad and educationally worthless and this virtually guarantees their demise (Meyer, 1981). Moreover most teacher-training institutions do not provide any formal training and practice in the selection and use of teaching aids (Maduna, 2002). This situation may lead to create problems for teachers when using teaching aids effectively at the teaching learning process.

In the current Sri Lankan Preschool Education context preschool teachers are struggling to cover a heavy syllabus especially in the preschools govern by the private sector. They are more towards to teaching desk work providing workbooks and work sheets. This has led them to minimize the use of creative and effective teaching aids in the teaching learning process. As such preschool teachers may face different problems in the teaching learning process due to lack of special training on using teaching aids appropriately. Eventually this may leads to diminish the productivity of preschool education for children and their learning.

Therefore identifying the problems that preschool teachers face when using teaching aids in the actual teaching learning process would be significant for preschool teachers to identify remedies to overcome their problems and to enhance the effectiveness and productivity of their teaching. Eventually this will positively help preschool children to receive an effective preschool education for their development.

Thus, this study attempted to identify the preschool teachers' perception on using teaching aids and the problems faced by teachers when making and using teaching aids in the teaching learning process. 


\subsection{Objectives of the study}

1. To identify the preschool teachers perceptions on using teaching aids in the teaching learning process.

2. To find out the problems faced by the preschool teachers when making and using teaching aids in the teaching learning process.

3. To identify suggestions to overcome the problems faced by the preschool teachers when making and using teaching aids in the teaching learning process.

\section{RESEARCH METHODOLOGY}

As the study focus on identifying the perceptions of preschool teachers and finding out the problems they face when making and using teaching aids the study employed quantitative method basically and qualitative methods.

\subsection{Population}

The population was of this study was the student teachers who have registered in the Diploma in Early Childhood and Primary Education offers by the Open University of Sri Lanka in the academic year of 2013/2014.

\subsection{Target population}

The target population was the student teachers who have registered in the Colombo regional center in both Sinhala and English mediums.

\subsection{Sample}

The sample of this study comprised of 60 Sinhala medium student teachers and 40 English medium student teachers who are in level 04 and work as preschool teachers.

\subsection{Data collection instruments}

A questioner was used as the major data collection instrument. Twenty two questions were asked by the student teachers, dividing in to two parts according to the objectives.

\section{RESULTS AND DISCUSSION}

The results showed that majority of the sample engage in teaching to children who are in the age level of $3-5$ years. From the sample $75 \%$ of preschool teachers in both mediums work in the private sector. Majority both medium preschool teachers are in the age level of $21-30$ years.

According to the working experience of preschool teachers $66 \%$ of Sinhala medium have 5-9 years working experience while 75 $\%$ of English medium teachers have $1-4$ years working experiences. In both mediums $90 \%$ of teachers have G.C.E Advanced Level qualifications. None of them had a degree qualification.

\section{a.) Preschool teachers' perceptions on using teaching aids in the teaching learning process.}

According to the responses the results are presented regardless of the medium of instruction. With reference to the preschool teachers' perception, $68 \%$ from the total sample perceive teaching aids are instruments which are used to introduce and promote the lesson. The rest of the sample had not responded to this question.

Table 1. Preschool teachers' perception on importance of using teaching aids

\begin{tabular}{|l|c|}
\hline Statements & Responses (\%) \\
\hline Yes, I strongly believe & 85 \\
\hline Not very much essential & 10 \\
\hline $\begin{array}{l}\text { No, I don't think it is } \\
\text { essential }\end{array}$ & 0 \\
\hline I don't have any idea about it & 5 \\
\hline
\end{tabular}

As table 1 shows majority (85\%) of teachers strongly believe that using teaching aids is important while $5 \%$ of the sample has no 
idea about it. $50 \%$ of the teachers from the sample have stated that they use teaching aids most of the time and $45 \%$ use teaching aids rarely while $5 \%$ do not use teaching aids at all. The reasons for not using teaching aids at all are lack of real objects to use and in the AMI method of teaching they have already designed materials for each activity.

Moreover the sample mentions that $57 \%$ of total population use teaching aids for selected lessons, at the same time 33\% use teaching aids for each session. Only 10\% from the total sample use teaching aids only when mention in the teacher's guide. Hence, the study could revealed that majority of teachers tend to use teaching aids at least for selected lessons.

Further, $58 \%$ of teachers from the total population state that they get benefits by using teaching aids all the time while $40 \%$ of them get benefits sometimes only. The rest of the sample says that they get benefit rarely. None of them state that they do not get any benefit. This further reveals that the preschool teachers have a considerable positive perception on teaching aids and its importance for the children's learning.

The following figure 1 illustrates the different ways the preschool teachers considered when making teaching Aids.

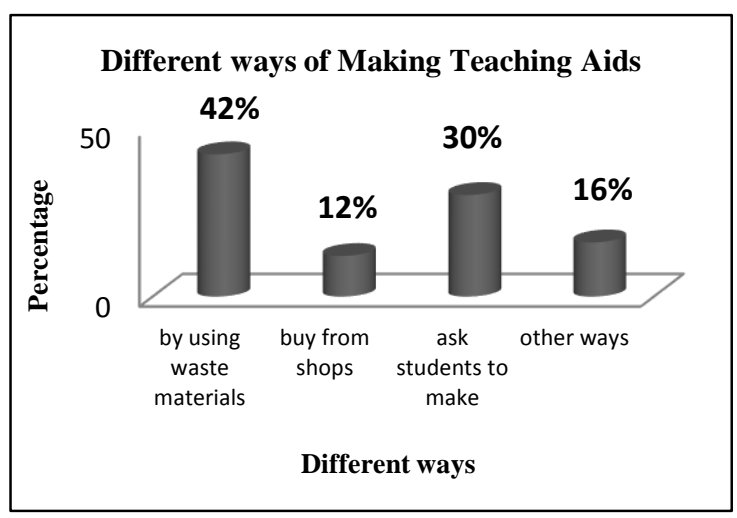

Figure 1. Ways of making teaching aids by preschool teachers
According to the above figure 1 it could be identified that the main ways of making teaching aids by the preschool teachers were using waste materials to make teaching aids and asking students to make. Still $12 \%$ of teachers from the sample buy teaching aids from shops. It shows that although many preschool teachers like to use teaching aids some teachers still do not prefer to make teaching aids by themselves. In addition, it could be revealed that some the teachers find other ways such as using materials provided by the school, borrowing teaching aids from the resource room.

Table 2. Purposes of using teaching aids by preschool teachers

\begin{tabular}{|l|c|}
\hline \multicolumn{1}{|c|}{ Purposes } & Responses (\%) \\
\hline To explain the facts more clearly & 70 \\
\hline To facilitate active learning & 64 \\
\hline To maintain good attention & 62 \\
\hline To increase students motivation & 61 \\
\hline $\begin{array}{l}\text { To give more opportunities to self } \\
\text { learning }\end{array}$ & 59 \\
\hline $\begin{array}{l}\text { To maintain liveliness in the } \\
\text { classroom }\end{array}$ & 40 \\
\hline To manage time & 32 \\
\hline
\end{tabular}

The above Table 2 shows the purposes of using teaching aids by the teachers in the teaching learning process. The purposes are stated according to the preferences given by the total sample. It could be identified that majority of the sample use teaching aids to explain the facts clearly. This further provides an evidence for the finding that the preschool teachers had a positive perception of teaching aids and its importance. Following table shows the mostly using teaching aids by the teachers.

As figure 2 given below indicates it could be identified the mostly used teaching aids by the preschool teachers were the teachers pictures, cards, photos and black board, books respectively whereas the least used teaching aids by the preschool teachers were TV/DVD/CD, audio cassettes.

It further revealed that the most popular teachings aids of the preschool teachers are the 
visual teaching aids and the least interest to use audio visual teaching aids such as computers and DVD $\mathrm{s}$ are still in the lower level though those teaching aids can add more creativity and novelty in the teaching learning process. Among the most popular teaching aids the pictures, cards and photos take the highest score which further reveals that preschool teachers more often use iconic teaching learning experiences for preschool children.

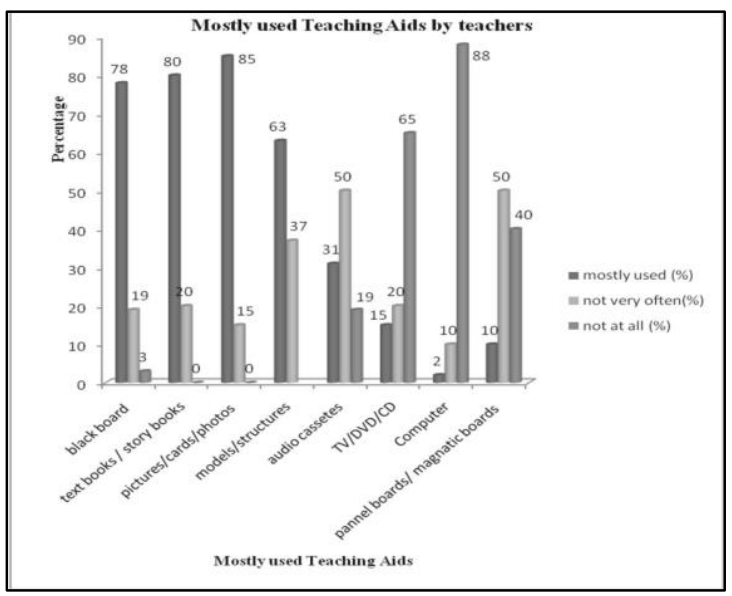

Figure 2. Mostly used teaching aids by the preschool teachers

\section{b.) Problems faced by the preschool teachers when making and using teaching aids}

Table 3. Problems of making teaching aids

\begin{tabular}{|l|c|}
\hline \multicolumn{1}{|c|}{ Problems } & Responses (\%) \\
\hline $\begin{array}{l}\text { Expensiveness of } \\
\text { materials }\end{array}$ & 27 \\
\hline $\begin{array}{l}\text { No time to make for each } \\
\text { lesson }\end{array}$ & 54 \\
\hline $\begin{array}{l}\text { Difficulty of } \\
\text { transportation }\end{array}$ & 15 \\
\hline Storage difficulty & 4 \\
\hline
\end{tabular}

According to the data showed in the Table 3.3 the main problem faced by the preschool teachers in making teaching aids is finding time to make teaching aids for each lesson. This further identifies that a sufficient time for teacher preparation specially for making teaching aids has not been allocated in their work duties. In addition teachers also feel that expensiveness of materials and difficulty in transportation make problems for them to make different effective teaching aids when teaching. Further teachers don't find storing difficulties as a huge problem that they had faced.

The following Figure 3 shows the problems the teachers faced when using teaching aids in the classroom.

Problems faced by the preschool teachers when using
teaching aids

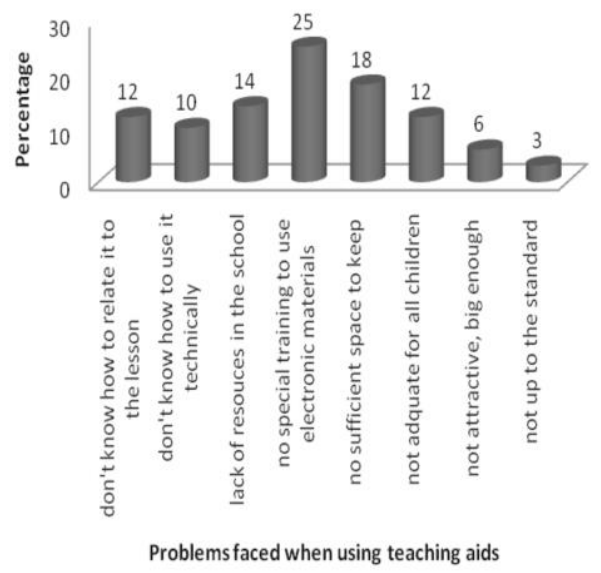

Figure 3. Problems face by preschool teachers when using teaching aids

According to the figure 3 lack of special training on using electronic materials such as computers, lack of space in the classroom to keep teaching aids and limited resources in their schools could be identified as main problems the teachers faced when using teaching aids in the classroom respectively. In addition not adequate for all children and lack of knowledge to relate teaching aids with the lesson could be identified as other problems the teachers faced. Whereas less attractiveness and poor standards are the least problems they faced when using teaching aids.

When compared with the rarely used teaching aids by the teachers and major problem they faced when using teaching aids, a connection could be identified between the two findings. It could be revealed that either teachers use audio visual teaching aids such as 
computers rarely because they don't have proper training on using them or since they don't have proper training they use those teaching aids in the classroom very rarely.

\section{c.) Suggestions to overcome problems}

In the study majority of the total sample suggested that to overcome the problems they face when making teachings, they need to share teaching aids among other teachers, make them only for selected lessons, use waste materials. To overcome the problems faced by the preschool teachers when using teaching aids in the teaching learning process, majority of total sample suggested arranging seminars, workshop to provide special training on using teaching aids effectively, making teaching aids that are durable, allocating a proper place to store teaching aids, create new teaching aids.

\section{CONCLUSION AND RECOMMENDATIONS}

According to the findings the following conclusions were made in this study. The study can concluded that majority of the preschool teachers possesses a precise perception on teaching aids and its significance in the teaching learning process.

Moreover the study concludes that though the preschool teachers are aware the functions and significance of using teaching aids, they limit the teaching aids to visual aids most often in the actual classroom due to the problems they faced with regard to lack of training of other audio visual teaching aids as well as lack of time for preparation of teaching aids. The study further concludes that the due to the problems they faced in relation to preparation and use of teaching aids the emphasis given on using teaching aids has been decreased.

Therefore the study recommends providing more emphasis on enhancing use of more teaching aids by providing proper awareness and training on using different types of teaching aids in the classroom effectively. Further the study can recommend encouraging teachers to prepare effective durable and creative teaching aids by allocating more time from their work schedule and using alternative materials.

\section{REFERENCES}

JACOBS M. Criteria for effective lesson preparation. Teaching- learning dynamics: a participative approach. Johannesburg: Heinemann. 1996; 53-92.

LINDEQUE B. Situation analysis. In M. Jacobs \& N. Gawe (Eds.), Teaching- learning dynamics: a participative approach. Johannesburg: Heinemann. 1996; 143-174.

MADUNA M. J. An analysis of the use of teaching aids and implecations for teaching and learning mathametics : in Qwa Qwa phase one schools (South Africa). (M. Ed) dissertation. 2002; Avalable on: http://spectrum.library. concordia.ca/1844/1/MQ82660.pdf.

MEYER J. Media, People and change- the arena of conflict. Instructa. 1981; 80(1) : $79-$ 84

MWAMWENDA T. Educational psychology: An African perspective ( $2^{\text {nd }}$ ed.), Durban: Butterworths. 1994.

ROMISZOWSKI. The selection and use of teaching aids. 1968; 11.

SPENCER K. The psychology of educational technology and instructional media. London: Routledge.1988.

VAN ROOYEN H \& VAN DER MERWE C. Teaching media. In M. Jacobs \& N. Gawe (Eds.), Teaching- learning dynamics: a participative approach. Johannesburg. 1996; 237-279.

YULE R \& STEYN P. Teaching and learning. Johannesburg. Lexicon. 1991. 